\title{
Do transitar: corpo, envelhecimento e morte em chave freudiana
}

On transiting: body, ageing and death in Freud's perspective

\section{Carlota María Ibertis*}

Resumo: O presente artigo examina o fenômeno do envelhecimento no que diz respeito ao corpo, à temporalidade e à morte do ponto de vista tanto de vivências subjetivas quanto da metapsicologia. Para tanto, considera-se a elaboração teórica que Freud desenvolve entre 1914 e 1920 que culmina com a publicação de Além do princípio do prazer.

Palavras-chave: Pulsão de Morte, Envelhecimento, Narcisismo, Luto

Abstract: This paper examines the phenomenon of ageing concerning the body, temporality and death from subjective experiences and a metapsychology point of view. For that purpose, this paper will be based on Freud's theory elaborated between 1914 and 1920 which culminates in the publication of Beyond the Pleasure Principle.

Keywords: Death Instinct, Ageing, Narcissism, Mourning

"Também o que é doloroso pode ser verdadeiro" Sigmund Freud

“... Todo pasa y todo queda pero lo nuestro es pasar Pasar haciendo caminos, caminos sobre la mar...”

Antonio Machado

\section{Corpo e tempo ou a vivência de envelhecer}

Dentre os desenhos de Goya, um chama especialmente a atenção, $O$ Tempo devorando os homens ${ }^{1}$. Na composição, um ancião - tradicionalmente associado com Saturno - de cabelos longos e despenteados, devora corpos de homens nus. Seu olhar, dirigido ao espectador, é especialmente inquietante, penetrante mistura de deboche cruel e

\footnotetext{
${ }^{1}$ MATILLA \& MARQUÉS, Sólo la voluntad me sobra. Goya. Dibujos, 247
}

* Professora Associada no Departamento de Filosofia da Universidade Federal da Bahia, Salvador, BA. E-mail: carlota.ibertis@gmail.com ORCID: https://orcid.org/0000-0001-8841-2074 
de promessa de um dia todos sermos alcançados por ele. A imagem terrificante leva à pergunta: somos feitos de tempo ou somos consumidos por ele? A tradição filosófica fala da temporalidade como constitutiva do ser do homem, de modo semelhante, a morte é apresentada como presente no horizonte de toda existência humana. Filósofos como Schopenhauer e Heidegger vão além disso defendendo que a morte é constitutiva do existir. No entanto, em nossa sociedade, a morte e o passo do tempo continuam a ser negados. É bem conhecida a advertência de Kant acerca da nostalgia:

A saudade dos suíços (e como fiquei sabendo por um general experiente também dos vestefalenses e dos pomerânios de algumas regiões), de que são acometidos quando deslocados a outros países, é o efeito de uma nostalgia suscitada pela evocação de imagens de despreocupação e proximidade social em seus anos de juventude, nostalgia dos lugares em que gozaram as alegrias simples da vida, ao passo que, em visitas posteriores, se acham bem frustrados em suas expectativas e também curados, sem dúvida pensando que tudo se modificou muito, mas de fato porque não podem passar novamente sua juventude ali $[\ldots]^{2}$.

A nostalgia, entendida como a dor perante algo que não está mais, ao contrário de como se pretende, não diz respeito a objetos, lugares ou pessoas, mas à própria juventude. Trata-se da dor perante a temporalidade e a finitude da vida.

Em 1915, Freud denunciava a atitude não franca e convencional perante a morte em períodos de paz. Assim, segundo ele, ao tempo que se declarava incontestável e inevitável o fato de que todos morreremos, procurava-se reduzi-lo ao silêncio pois "...no inconsciente cada um de nós está convencido de sua imortalidade” ${ }^{3}$. Em contraposição, Freud acreditava que durante a guerra, a vida tornara-se "mais interessante" ao recuperar seu "pleno conteúdo" pela consciência da condição de mortais ${ }^{4}$. Como sabido, não passariam muitos anos até ele postular a pulsão de morte como constitutiva de todo organismo vivente.

$\mathrm{Na}$ cultura contemporânea, as formas de negação do envelhecer e da morte diversificam-se sob a enganosa proclamação da "liberação do corpo" paradoxalmente regida por uma "norma de discrição" para melhor esconder o corpo real do quotidiano, saudável ou doente, e por uma "norma de controle" cujo imperativo é cultivar o corpo obedecendo valores sociais ${ }^{5}$ em uma atitude de crescente moralização:

Quem envelhece é então tido como responsável de seu envelhecimento. O que se apresenta como uma emancipação - devir sujeito ativo de seu

\footnotetext{
${ }^{2}$ KANT, Antropologia de um ponto de vista pragmático, 77.

${ }^{3}$ FREUD, Considerações atuais sobre a guerra e a morte, 230.

${ }^{4}$ FREUD, Considerações atuais sobre a guerra e a morte, 233.

${ }^{5}$ WAINTRATER, Le corps de la vieillesse dans la culture contemporaine, 20.
} 
envelhecimento - se muda em um imperativo indutor de culpabilidade e vergonha. Aquele cujo corpo declina é considerado como um ser imoral e sem vontade. O envelhecimento vem se acrescentar aos sete pecados capitais de nossa sociedade judeu cristã. Demasiadamente presente, o corpo do velho é uma lembrança insuportável da condição humana. É por isso que ele deve ser modelado, remodelado, corrigido no máximo possível para ser relegado quando não responder mais às normas impiedosas do irrepreensível ${ }^{6}$.

O corpo velho, sinal dos limites da nossa condição e prenúncio da morte, é o paradigma do que deve ser negado. A moralização do corpo a que alude a autora conduz à oscilação entre um discurso prolixo de um otimismo voluntarista acerca do "bem envelhecer" de pessoas idosas sempre jovens e tonificadas e um discurso da doença, do handicap e da morte sem consideração de qualquer forma processual. À velhice falta uma representação nuançada e realista. Ao contrário, ela é mostrada em imagens extremas de serenidade e sabedoria ou de agressividade amarga e repulsiva.

Tal simplificação parece indicar a marcada dificuldade em lidar com o passo do tempo e a castração última que representa a morte ${ }^{7}$. E é, justamente, no corpo em que esses mais claramente se manifestam. Em condições de saúde e juventude, os órgãos silenciam até que inesperadamente põem em evidência o caráter irreversível do transcurso temporal presentificando a finitude.

Norberto Bobbio descreve a vivência do envelhecimento no seu corpo da seguinte maneira:

A verdade é que - ainda que seja difícil para quem é mais jovem - o descenso a parte nenhuma é longo, mais longo do que teria imaginado, e lento, até o ponto de parecer quase imperceptível (não para mim). O descenso é contínuo e, o que é pior, irreversível: tu desces um pequeno degrau cada vez, mas uma vez posto o pé no degrau inferior, sabes que não voltarás ao degrau mais alto. Não sei quantos ficam ainda. Mas não me cabe dúvida de uma coisa: são cada vez menos ${ }^{8}$.

Envelhecer traz junto de si a expectativa com data incerta da morte certa experimentada por alguns como ameaça e por outros como promessa. Em todo caso, observa Bobbio, a velhice não está cindida do resto da vida anterior: é a continuação da

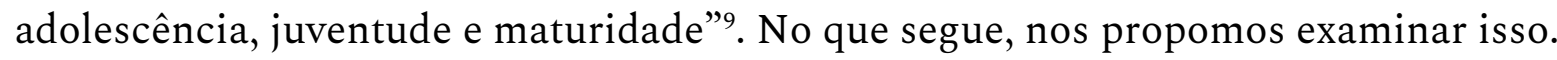

\footnotetext{
${ }^{6}$ WAINTRATER, Le corps de la vieillesse dans la culture contemporaine, 22.

${ }^{7}$ WAINTRATER, Le corps de la vieillesse dans la culture contemporaine, 22-24.

${ }^{8}$ BOBBIO, De Senectute, 48.

${ }^{9}$ BOBBIO, De Senectute, 40.
} 


\section{Pulsão de morte e processo de envelhecer}

É de consenso que Freud começa a elaborar as questões que desembocam na última formulação do dualismo pulsional antes do Além do princípio do prazer. A controvérsia gira em torno do alcance desse "antes". Como de sólito, as interpretações acerca do "movimento do pensamento" 10 freudiano diferem. A ideia de uma pulsão destrutiva é uma novidade cuja gestação data da época da elaboração da introdução ao narcisismo ou já estaria implícita desde os inícios da teorização psicanalítica?

Como leitor de filosofia e cientista da área médica, é razoável pensar que a questão da morte de um organismo se encontre presente desde sempre no seu universo de perguntas e problemas. É também razoável pensar que a circunstância da primeira guerra tenha influenciado na sua elaboração como vários textos entre os anos de 1914 e 1919 assim o sugerem ${ }^{11}$. A questão é a partir de quando Freud atribui à agressividade o estatuto de pulsão elementar autônoma.

De acordo com Monzani, a concepção freudiana desde o Projeto identifica a tendência primordial do aparelho psíquico a descarregar toda excitação e cancelar todo aumento da mesma. Desde então, o prazer, entendido como descarga e, portanto, princípio que rege o aparelho, possui uma significação que, retrospectivamente após a postulação da pulsão de morte, poderá ser caracterizada de mortuária ${ }^{12}$. Contudo, considerar o fenômeno da compulsão à repetição e o desprazer por ela acarretado, leva Freud a desestimar o prazer enquanto princípio determinante de toda a vida psíquica para passar a atribuir-lhe o caráter de tendência a serviço de uma função:

...à qual cabe tornar o aparelho psíquico isento de excitação, ou conservar o montante de excitação dentro dele constante ou o menor possível. Ainda não podemos nos decidir por nenhuma dessas concepções, mas notamos que a função assim determinada participaria do universal empenho de todos os viventes: retornar à quietude do mundo inorgânico ${ }^{13}$.

Em outras palavras, no texto de 1920 fica explícito que a tendência primordial à descarga máxima da excitação é a expressão de uma tendência para a morte e que o princípio do prazer, a serviço desta, mesmo que dê conta de uma parcela importante dos fenômenos psíquicos, não explica a totalidade desses ${ }^{14}$.

Embora no círculo psicanalítico o tema da agressividade tenha aparecido com antecedência, Freud não lhe atribui estatuto de pulsão separada senão até publicar o texto

\footnotetext{
${ }^{10}$ Em Freud: o movimento de um pensamento, Monzani descreve a elaboração teórica freudiana como efetuando um movimento espiralado.

${ }^{11}$ Referimo-nos a textos como De Guerra e morte, A transitoriedade, Luto e melancolia.

${ }^{12}$ MONZANI, O paradoxo do prazer em Freud, 164.

${ }^{13}$ FREUD, Além do princípio do prazer, 236-7.

${ }^{14}$ MONZANI, O paradoxo do prazer em Freud, 164.
} 
Além do princípio do prazer ${ }^{15}$. Em todo caso, parece relevante notar que após mais de vinte anos do Projeto, Freud insiste em uma perspectiva científico-especulativa, dessa vez de corte biológico, com o objetivo de amarrar os fios soltos da tendência à descarga de excitação, da compulsão à repetição e da agressividade. A eliminação de excitação ganha uma nova dimensão, sendo pensada não para dar conta apenas do psiquismo, mas "como inerente à própria vida como um todo" cuja tendência última é retornar ao estado anterior de ausência total de estimulação, ou seja, ao estado inanimado ${ }^{16}$.

Assim, a reformulação do dualismo pulsional supõe que a imbricação entre Eros e Tanatos define o curso vital, entendido como desvio em relação ao estado inorgânico, ponto de partida e de retorno. Dada essa premissa e sendo a pulsão um conceito fronteiriço entre soma e psique, poder-se-ia pensar o envelhecer em termos do processo de separação em que progressivamente Tanatos vai ganhando preeminência sobre Eros até alcançar a meta final pois "o objetivo de toda vida é a morte..." ${ }^{17}$. Mas, é preciso salientar, não se trata de qualquer morte, “... o organismo pretende morrer apenas a seu modo..."18 o que envolve causas internas sugerindo também a noção de envelhecer.

\section{Olhar metapsicológico sobre o envelhecimento}

É possível conceber o envelhecimento enquanto objeto teórico na perspectiva freudiana? Embora Freud manifeste preocupação pessoal com a velhice, na sua obra se encontram muito poucas referências ao fenômeno. Em termos clínicos, são conhecidas as afirmações sobre a impossibilidade de análise para além da idade de cinquenta anos devido, em primeiro lugar, à falta de plasticidade dos processos psíquicos e, portanto, as pessoas idosas não seriam mais educáveis e, em segundo lugar, ao fato de que o volume do material a ser trabalhado prolongaria indefinidamente o tratamento ${ }^{19}$. Em termos teóricos, Freud não se ocupa do fenômeno, o que não significa necessariamente que não se possa pensar acerca do assunto do ponto de vista da sua teoria.

Ainda que a velhice e o envelhecimento sejam fenômenos abordados por diversos discursos e saberes desde o biológico passando pelo médico até o antropológico,

\footnotetext{
${ }^{15}$ Em nota a esse texto, o próprio Freud menciona elogiosamente o trabalho que Sabina Spielrein publica em 1912 “A Destruição como causa do Vir-a-ser” e a tentativa de Stärcke de identificar a libido com um impulso biológico para a morte (2010, p. 227). A esse respeito e um pouco maliciosamente, Peter Gay sugere que o fato de Adler e Jung defenderem teses que, de alguma maneira, também antecipariam a ideia de um impulso destrutivo pode ter influenciado na demora freudiana em aceitar o estatuto pulsional da agressividade (1989, p. 364).

${ }^{16}$ CAROPRESO \& SIMANKE, Entre o corpo e a consciência, 183.

${ }^{17}$ FREUD, Além do princípio do prazer, 204.

${ }^{18}$ FREUD, Além do princípio do prazer, 204.

${ }^{19}$ FREUD, Psicoterapia,342.
} 
sociológico, etc., aqui nos interessa a perspectiva específica da psicanálise. Não é o caso, então, de subordinar o discurso ao biológico - nem a nenhum outro -, nem de desconhecêlo, mas de tentar uma caracterização metapsicológica do envelhecimento ${ }^{20}$. Para tanto, é preciso considerar os pontos de vista dinâmico, econômico e tópico.

Uma primeira dificuldade na tentativa de compreender o envelhecimento enquanto objeto metapsicológico reside em que os processos inconscientes são atemporais ${ }^{21}$ e envelhecer diz respeito a um processo de modificações que pressupõe temporalidade. Como conciliar ambas características na tarefa de modelizar o envelhecimento na perspectiva do inconsciente?

Responder essa pergunta requer considerar que o fato de o inconsciente e o Id não obedecerem às leis do tempo não exclui que a constituição da psique tenha uma história que determina seu funcionamento. Em primeiro lugar, Freud concebe o aparelho psíquico constituído por estratificações sucessivas de associações à maneira do aparelho de linguagem. Com base na tese acerca da retrogressão funcional de Hughlings Jackson, a diacronia dos processos psíquicos outorga a matriz sobre a qual explicar a psicopatologia ${ }^{22}$. Assim como a afasia supõe a volta a um estágio anterior da aquisição da linguagem, as psiconeuroses obedecem ao retrocesso a estádios de organização psíquica anteriores descritos em Três ensaios sobre a teoria da sexualidade e os sonhos a formas mais primitivas de representação descritas em $A$ Interpretação dos sonhos.

Em um acréscimo de 1914 ao capítulo VII dessa última, Freud estabelece a distinção entre os tipos de regressão temporal, formal e tópica. A concepção histórica do aparelho psíquico estabelece uma trama peculiar na organização do material mnêmico que pode ser descrita desde as três perspectivas sem deixarem de ser uma única:

A propósito da regressão, observemos ainda que na teoria da formação dos sintomas neuróticos ela tem um papel não menos relevante que na teoria dos sonhos. Diferenciamos três tipos de regressão: a) uma regressão topológica, no sentido do esquema dos sistemas $\psi$ aqui desenvolvido, b) uma temporal, quando se trata de um retorno a formações psíquicas mais antigas, e c) uma regressão formal, quando modos primitivos de expressão e representação substituem os habituais. Mas todos os três tipos de regressão, no fundo, são um só e coincidem na maioria dos casos, pois, a mais antiga é, ao mesmo tempo, a mais primitiva na forma e, na topologia psíquica, a mais próxima à extremidade perceptiva ${ }^{23}$.

Às diferentes formas de regressão correspondem a sucessão do tipo de processos psíquicos, a complexificação progressiva das formas de representação e a ordenação dos

\footnotetext{
${ }^{20}$ ASSOUN, Le vieillissement saisi par la psychanalyse, 170.

${ }^{21}$ FREUD, O Inconsciente, 128.

${ }^{22}$ FREUD, Sobre a concepção das afasias, 112.

${ }^{23}$ FREUD, A Interpretação dos sonhos, 599.
} 
sistemas mnêmicos. Adiante e atrás, antes e depois, do mais simples ao mais complexo são as três dimensões em que se desenvolve a vida psíquica e que estabelecem as formas regressivas.

Em segundo lugar, Freud delineia o esquema da história do desejo de cada indivíduo estabelecendo um entremeado de pulsões egoicas e sexuais as que irão se acrescentar posteriormente as agressivas. Como conhecido, desde a primeira vivência de satisfação passando pelas diversas configurações das pulsões, inicialmente parciais e múltiplas, tem lugar um processo de unificação em direção à organização genital ${ }^{24}$. Do prazer autoerótico sentido ao realizar funções vitais ao narcisismo para desembocar no prazer genital na satisfação por meio do objeto amoroso, o percurso caracteriza-se pela complexidade e singularidade com que se combinam os diversos componentes e processos envolvidos ${ }^{25}$.

Todavia, não se trata apenas do processo das pulsões sexuais, mas também de considerar o das pulsões egoicas. Estas também "passam por um importante desenvolvimento, que não é nem totalmente independente do da libido nem desprovido de efeito contrário a ela" 26 . Inicialmente, regidos pelo princípio do prazer, ambos tipos de pulsões se complementam como o deixa manifesto o prazer sexual anaclítico. Mas, sob a influência de Ananké, as pulsões egoicas passam a obedecer antes e de maneira mais sólida ao princípio de realidade buscando obter "um prazer assegurado pela consideração da realidade" que resulta adiado e diminuído ${ }^{27}$.

Por fim, em Além do princípio do prazer, após revisar formulações anteriores da concepção dualista das pulsões, Freud enuncia a oposição entre pulsões de vida e pulsões de morte postulando a sua mistura, identificável na presença de impulsos sádicos no amor objetal e no estágio oral da organização libidinal ${ }^{28}$. Desse modo, se a vida psíquica do indivíduo está regida pelas pulsões de vida e de morte - fazendo uma adaptação da questão proposta por Assoun ${ }^{29}$ - a pergunta a ser feita é: como o que chamamos envelhecimento afeta a aptidão para fruir, se relacionar com os outros e com a realidade na sua tradução psíquica?

A história singular da constituição psíquica, própria de cada indivíduo, tecida do delicado - e não isento de conflitos - entramado pulsional implica na formação de pontos de fixação relativos às diversas fases (em termos kleinianos, posições) para eventuais processos de regressão. Assim, se na pré-história infantil, às modificações corporais

\footnotetext{
${ }^{24}$ FREUD, Três ensaios sobre a teoria da sexualidade, 107-111.

${ }^{25}$ FREUD, Três ensaios sobre a teoria da sexualidade, 136-7.

${ }^{26}$ FREUD, Conferências introdutórias à psicanálise, 466-7.

${ }^{27}$ FREUD, Conferências introdutórias à psicanálise, 474.

${ }^{28}$ FREUD, Além do princípio do prazer, 225-6.

${ }^{29}$ Assoun formula a questão em termos da libido. Pelas razões mencionadas nos parágrafos imediatamente anteriores, optamos por considerar a perspectiva das pulsões em conjunto.
} 
correspondem modificações pulsionais ${ }^{30}$, caberia esperar que ao surgirem limitações nas capacidades corporais na idade adulta também aconteçam mudanças na equação pulsional do indivíduo. Ao que tudo parece indicar, não havendo fase pós-genital, como enfatiza Assoun, o caminho possível é regressivo.

Nesse sentido, o acontecimento constitutivo do envelhecimento parece residir na crise narcísica da relação de objeto que alcançaria o âmago da articulação das pulsões fundamentais. $\mathrm{Na}$ transformação pulsional própria da velhice, Assoun enxerga a reatualização de certo tipo de escolha de objeto por apoio que indicaria a reversão sobre um tipo de escolha de objeto infantil. Essa afinidade estrutural entre a criança, tal como descrita em Três ensaios de teoria sexual, e o idoso lhe sugere uma "homologia fascinante" entre as posições infantil e do envelhecimento com base no anaclítico. Mais do que nunca “encontrar o objeto sexual não é senão reencontrá-lo"31.

Essa espécie de reativação "reconduz" o sujeito a suas necessidades de autoconservação renovando o interesse por tudo o concernente ao bem-estar do corpo próprio. Para o psicanalista, tal situação difere de alguma variante de enfraquecimento da energia. Se por uma parte, as mudanças alteram progressivamente a fruição genital demandando o correspondente trabalho de luto; por outra, o refluxo do sujeito sobre suas posições narcísicas parece liberar uma potencialidade criativa e lúdica que se contrapõe à “seriedade" exigida pelo investimento objetal ${ }^{32}$. Em ambos casos, é necessária uma grande quantidade de investimento.

Dessa maneira, se desenha um movimento segundo o qual cada tipo de pulsão vai recuperando de forma gradual a autonomia no concernente ao seu fim. As imagens alternativas sobre a velhice de agressividade triste opostas às de serenidade amável mostrariam a preeminência das pulsões de vida nestas últimas enquanto que aquelas sugeririam os avatares do predomínio da desunião de Eros e Tanatos.

Do ponto de vista tópico, pode-se notar no envelhecimento por uma parte, um relaxamento das relações entre Superego e Id em função de um menor impacto do conflito edipiano na história de cada um, manifesto na reabilitação das imagos parentais na velhice. Por outra, o trabalho do luto pelo objeto perdido, seja o corpo juvenil, sejam as possibilidades desperdiçadas, etc., desemboca em um redimensionamento do Eu e suas ilusões perdidas ${ }^{33}$. Com efeito, no luto normal, o Eu, defrontado com a possibilidade da própria extinção à semelhança da do objeto perdido, é levado a romper o vínculo com este movido pela "soma das satisfações narcísicas em estar vivo" ${ }^{4}$. O luto um dia acaba.

\footnotetext{
${ }^{30}$ Como já mencionado, não se trata de subordinar a reflexão presente ao discurso biológico, mas de reconhecer as condições de possíveis mudanças dada a natureza fronteiriça da pulsão.

${ }^{31}$ ASSOUN, Le vieillissement saisi par la psychanalyse, 174-5.

${ }^{32}$ ASSOUN, Le vieillissement saisi par la psychanalyse, 176.

${ }^{33}$ ASSOUN, Le vieillissement saisi par la psychanalyse, 177.

${ }^{34}$ FREUD, Luto e melancolia, 189.
} 


\section{Transitoriedade}

Envelhecer implica na urgência de revisar a avaliação, normalmente negativa, acerca do caráter transitório da existência. Encontramos em Schopenhauer a expressão da resistência perante o passo do tempo:

Ainda que envelheçamos muito, em nosso íntimo sentimo-nos exatamente os mesmos que éramos na juventude, ou melhor, na infância. Isso que permanece inalterado, sempre igual e que não envelhece com o passar do tempo é o cerne de nossa essência, que não reside no tempo e, justamente por essa razão, é indestrutível ${ }^{35}$.

Poder-se-ia dizer que em algum sentido somos sempre a criança que fomos, mas em outro, não somos mais ela. Como antes mencionado, aceitar a temporalidade é um desafio que exige da nossa parte um trabalho profundo de elaboração sem garantia de sucesso.

Reflexo do anterior, a transitoriedade acarreta perda de sentido, desvalorização ou desencanto perante o que é belo. Assim, a beleza de uma paisagem no verão, do corpo humano jovem, de uma flor, de uma obra de arte, de uma produção intelectual, tudo isso tem seu valor diminuído pela antecipação da dor que entranha o luto. Acerca deste, Freud declara: "Só percebemos que a libido se apega a seus objetos e, mesmo quando dispõe de substitutos, não renuncia àqueles perdidos" ${ }^{36}$. Para acrescentar mais adiante acerca do luto:

Tendo renunciado a tudo que perdeu, ele terá consumido a si mesmo, e nossa libido estará novamente livre - se ainda somos jovens e vigorosos para substituir os objetos perdidos por outros novos, possivelmente tão ou mais preciosos que aqueles ${ }^{37}$.

A pergunta se impõe imediatamente: e se não formos nem jovens, nem vigorosos? Freud não dá uma resposta explícita. É preciso buscá-la em cada um, chegada a hora. Em primeira pessoa, Bobbio fala da sua experiência:

Direi com uma só palavra que tenho uma velhice melancólica, entendendo a melancolia como a consciência do não alcançado e do já não mais alcançável. Se ajusta bem a isso a imagem da vida como um caminho, no qual a meta se desloca sempre para adiante, e quando acreditas tê-la alcançado não era a que te havias figurado como definitiva. A velhice converte-se então no momento em que tens a plena consciência de que não

\footnotetext{
${ }^{35}$ SCHOPENHAUER, $A$ arte de envelhecer, 61.

${ }^{36}$ FREUD, A transitoriedade, 250.

${ }^{37}$ FREUD, $A$ transitoriedade, 251-2.
} 
somente não tens percorrido o caminho, senão que já não te resta tempo para percorrê-lo, e deves renunciar a alcançar a última etapa.

A melancolia está temperada, no entanto, pela constância dos afetos que o tempo não consumiü ${ }^{38}$.

$\mathrm{Na}$ literatura Freud reconhece "a condição sob a qual poderíamos nos reconciliar com a morte: de que por trás de todas as vicissitudes da vida nos restasse ainda uma vida intacta”. Ao contrário, na vida real sucede como em um jogo de xadrez, em que não há segunda chance ${ }^{39}$. A revolta contra a condição de seres mortais é, na ótica freudiana, produto de nosso desejo que supõe não aceitar que: "Também o doloroso pode ser verdadeiro" ${ }^{40}$. Numa inversão radical de perspectiva - com ecos do Carpe diem! -, Freud salienta a maior valorização da transitoriedade: “a limitação da possibilidade de fruição aumenta a sua preciosidade" ${ }^{41}$.

\section{Considerações inconclusivas}

A despeito da crença racional no caráter finito da vida, vivemos como se o tempo não corresse. Permanecendo mais ligados à onipotência infantil, devemos fazer esforços cada vez que precisamos nos situar novamente na perspectiva da idade que vai mudando. Se, por uma parte, como Le Gouès observa, existem marcadores culturais cuja função é a de indicar a entrada nas diferentes idades, corrigindo erros da percepção temporal, e o olhar dos outros e as progressivas limitações corporais contrariam a negação do tempo urgindo delicados ajustes identitários ${ }^{42}$, por outra, a sociedade também oculta os inevitáveis impactos desse no corpo. Impõe-se o imperativo cultural de conquistar uma velhice jovial sem maiores mudanças enquanto se multiplicam gestos, mais ou menos sutis, de discriminação pela idade avançada. Envelhecer supõe, então, o desafio de encontrar novas maneiras de interagir com os outros e de se relacionar consigo mesmo.

Do ponto de vista metapsicológico, o envelhecer se apresenta como regressão temporal a formas de organização centradas no interesse do corpo próprio. Nesse sentido, é sugestiva a ideia de que mais do que por mudanças econômicas no sentido de diminuição da energia, o envelhecimento parece caracterizar-se topicamente pelo relaxamento do rigor das interdições da instância superegoica bem como dinamicamente pelas alterações na estrutura conflitiva das pulsões, em direção a uma progressiva desunião.

\footnotetext{
${ }^{38}$ BOBBIO, De Senectute, 42-3.

${ }^{39}$ FREUD, Considerações atuais sobre a guerra e a morte, 233.

${ }^{40}$ FREUD, A transitoriedade, 248.

${ }^{41}$ FREUD, A transitoriedade, 249.

${ }^{42}$ LE GOUÈS, Le stade des rides, 1043-4.
} 
Podemos dizer, junto com Polard, que o processo de envelhecimento confronta o indivíduo com seu desejo, com o tempo e com a morte mediante um trabalho psíquico, consciente e inconsciente, iniciado na assim chamada "crise da meia idade". Dir-se-ia que o mesmo coloca à prova o narcisismo de cada um à medida que demanda diversos lutos ${ }^{43}$. Uma experiência de estranheza em relação a si e ao mundo antes vivenciado como familiar insinua-se em quem envelhece. Após a segurança característica da maturidade, surge novamente a incerteza do desconhecido requerendo novas doses de coragem que podemos qualificar de existencial.

Para finalizar, como metáfora - ou, talvez melhor, como síntese - do transitar por essa etapa da vida, lembremos de outro desenho de um Goya mais maduro - considerado um autorretrato simbólico - em que um ancião caminha com ajuda de dois bastões enquanto o seu olhar reflete a tensão entre as carências da velhice e o impulso de continuar avançando. No mesmo lê-se: "Ainda apreendo" 44

\section{Referências}

ASSOUN, P-L, Le vieillissement saisi par la psychanalyse. Communications, 37, 1983. Disponível em:< https://www.persee.fr/doc/comm 0588-8018 1983 num 37 $11559>$ Acesso em 10 maio 2020

BOBBIO, N. De Senectute y otros escritos autobiográficos. Trad. Esther Benítez, Madrid: Taurus, 1997.

CAROPRESO, F \& SIMANKE, R.T. Entre o corpo e a consciência. São Carlos: EdUFSCar, 2011.

FREUD, S. Sobre a concepção das afasias. Um estudo crítico. Trad. Emiliano de Brito Rossi. In Obras Incompletas. Belo Horizonte: Autêntica Editora, 2013.

FREUD, S. Interpretação dos sonhos. In: Obras Completas. Trad. e notas Paulo César de Souza. São Paulo: Companhia das Letras, 2019, v. 4.

FREUD, S. Psicoterapia. In: Obras Completas. Trad. e notas Paulo César de Souza. São Paulo: Companhia das Letras, 2016a, v. 6.

FREUD, S. Três ensaios sobre a teoria da sexualidade. In: Obras Completas. Trad. e notas Paulo César de Souza. São Paulo: Companhia das Letras, 2016b, v. 6.

FREUD, S. Considerações atuais sobre a guerra e a morte. In: Obras Completas. Trad. e notas Paulo César de Souza. São Paulo: Companhia das Letras, 2010a, v. 12.

\footnotetext{
${ }^{43}$ POLARD, Vieillissement, 1.

${ }^{44}$ MATILLA \& MARQUÉS, Sólo la voluntad me sobra. Goya. Dibujos, 366.
} 
FREUD, S. A transitoriedade. In: Obras Completas. Trad. e notas Paulo César de Souza, São Paulo: Companhia das Letras, 2010b, v. 12.

FREUD, S. O Inconsciente. In: Obras Completas. Trad. e notas Paulo César de Souza. São Paulo: Companhia das Letras, 2010c, v. 12.

FREUD, S. Luto e melancolia. In: Obras Completas. Trad. e notas Paulo César de Souza. São Paulo: Companhia das Letras, 2010d, v. 12.

FREUD, S. Conferências introdutórias à psicanálise. In: Obras Completas. Trad. Sergio Tellaroli, revisão Paulo César de Souza. São Paulo: Companhia das Letras, 2014, v. 13.

FREUD, S. Além do princípio do prazer. In: Obras Completas. Trad. e notas Paulo César de Souza. São Paulo: Companhia das Letras, 2010e, v. 14.

FREUD, S. O eu e o id. In Obras Completas. Trad. e notas Paulo César de Souza. São Paulo: Companhia das Letras, 2010f, v. 16.

GAY, P. Freud: uma vida para o nosso tempo. Trad. Denise Bottman. São Paulo: Companhia das Letras, 1989.

KANT, I. Antropologia de um ponto de vista pragmático. Trad. Clélia Aparecida Martins. São Paulo: Iluminuras, 2006.

LE GOUÈS, G. Le stade des rides. In: Revue française de psychanalyse, v. 69 Disponível em: <https://www.cairn.info/revue-francaise-de-psychanalyse-2005-4-page-1043.htm> Acesso em: 10 maio 2020.

MATIllA, J.M e MARQUÉS, M.B. MENA Solo la voluntad me sobra: Goya. Dibujos. Madrid: Museo Nacional del Prado, 2019.

MONZANI, L. R. O paradoxo do prazer em Freud. In: FULGENCIO, L. e SIMANKE, R.T, (orgs.) Freud na filosofia brasileira. São Paulo: Escuta, 2005.

MONZANI, L.R. Freud: o movimento de um pensamento. Campinas: UNICAMP, 1989.

POLARD, J. Vieillissement. In: Dictionnaire international de la psychanalyse. Dir. Alain de Mijolla, Edition Pluriel - Fayard, 2013. Disponível em:< http://psychologiespolard.fr/vieillissement/ > Acesso em 23 abril 2020.

SCHOPEnHAUER, A. A arte de envelhecer ou Senilia. Trad. Karina Jannini, org e introd. Franco Volpi. São Paulo: wmf martins fontes, 2016.

WAINTRATER, R. Le corps de la vieillesse dans la culture contemporaine. In: LatinAmerican Journal of Fundamental Psychopathology. Online. São Paulo, v. 5, n. 1, p. 19-31, maio 2008. Disponível em: < http://pepsic.bvsalud.org/scielo.php?script=sci_arttext\&pid=S1677-03582008000100003> Acesso em: 02junho 2020. 